\title{
The early years of the ESHG leading to the reform of 1988 and the spirit of the Sestri Levante school
}

\author{
Giovanni Romeo ${ }^{\star, 1}$, Eberhard Passarge ${ }^{2}$ and Albert de la Chapelle ${ }^{3}$ \\ European Journal of Human Genetics (2017) 25, S6-S12; doi:10.1038/ejhg.2017.142
}

At the Third International Congress of Human Genetics in Chicago in September 1966 a group of human geneticists from Europe met and agreed that there should be a European Society of Human Genetics (ESHG). This was formally established in 1967, as reviewed elsewhere in this issue by Peter S Harper. As two of us (EP and AdlC) attended the discussion in 1966 and all three were involved subsequently in the early development of the ESHG we would like to add a few comments. Following its first annual meeting in 1967 in Copenhagen, the ESHG held meetings each year in various European cities arranged by different colleagues as local hosts, but not yet organised as a scientific society comparable to the American Society of Human Genetics.

At the 1988 ESHG meeting in Cardiff a process to reform the Society was started as described by Brunner and Harper in this issue of the Journal (EJHG, 2017). In April of the same year 108 young geneticists from 16 European countries travelled to Sestri Levante, Italy, to attend the first week-long course in Medical Genetics, taught by the late Victor A McKusick (1921-2008) and by many of the European medical geneticists of the time (see Figures 1 and 2).

The model for this course was the 'Short Course in Medical and Mammalian Genetics' held in Bar Harbor, Maine, organised each year by Victor A McKusick and attended in 1968 by some young European participants, including the three of us. The support of the Istituto Gaslini (Genoa) and of the Federation of European Societies of Biochemistry (FEBS) made it possible to start the European equivalent of the Bar Harbor course 20 years later; this was quite labour-intensive as shown by its tight scientific schedule (Figure 3), consisting of morning lectures and afternoon practical workshops (but also characterized by long lunch breaks of about $2 \mathrm{~h}$ dedicated to the delicacies of Genoese cuisine...).

During subsequent years this model developed further into many more specialised courses (Cancer Genetics, Genetic Counselling, Molecular Cytogenetics, Eye Genetics, etc.) that became to be known as the European School of Genetic Medicine (ESGM). The 30th edition of the main ESGM course took place at the beginning of May 2017 in Bertinoro, Italy, with the new name 'Clinical Genomics and NGS'. It was attended by 89 students from all over the world (37 countries, Figure 4). Most of the ESGM courses have been supported consistently by ESHG fellowships. In what is more relevant for the history of ESHG, some of the highly motivated faculty of the 1988 course became the leaders of the reformed ESHG in later years, after the new statutes

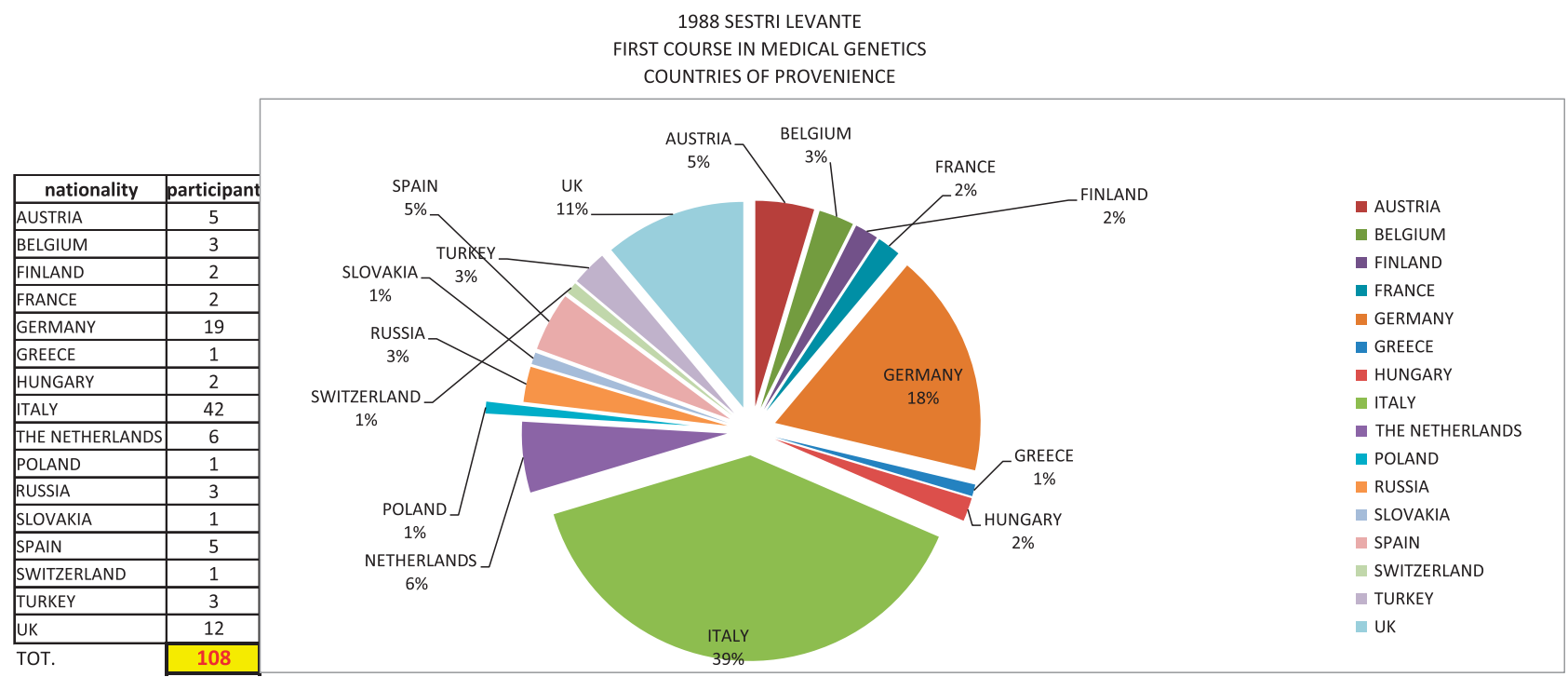

Figure 1

\footnotetext{
${ }^{1}$ University of Bologna, Department of Medical and Surgical Sciences, Bologna, Italy; ${ }^{2}$ Universität Duisburg-Essen, Institut für Humangenetik, Hufelandstr, Duitsland; ${ }^{3}$ Human Cancer Genetics Program, The Ohio State University, Columbus, Ohio, USA 


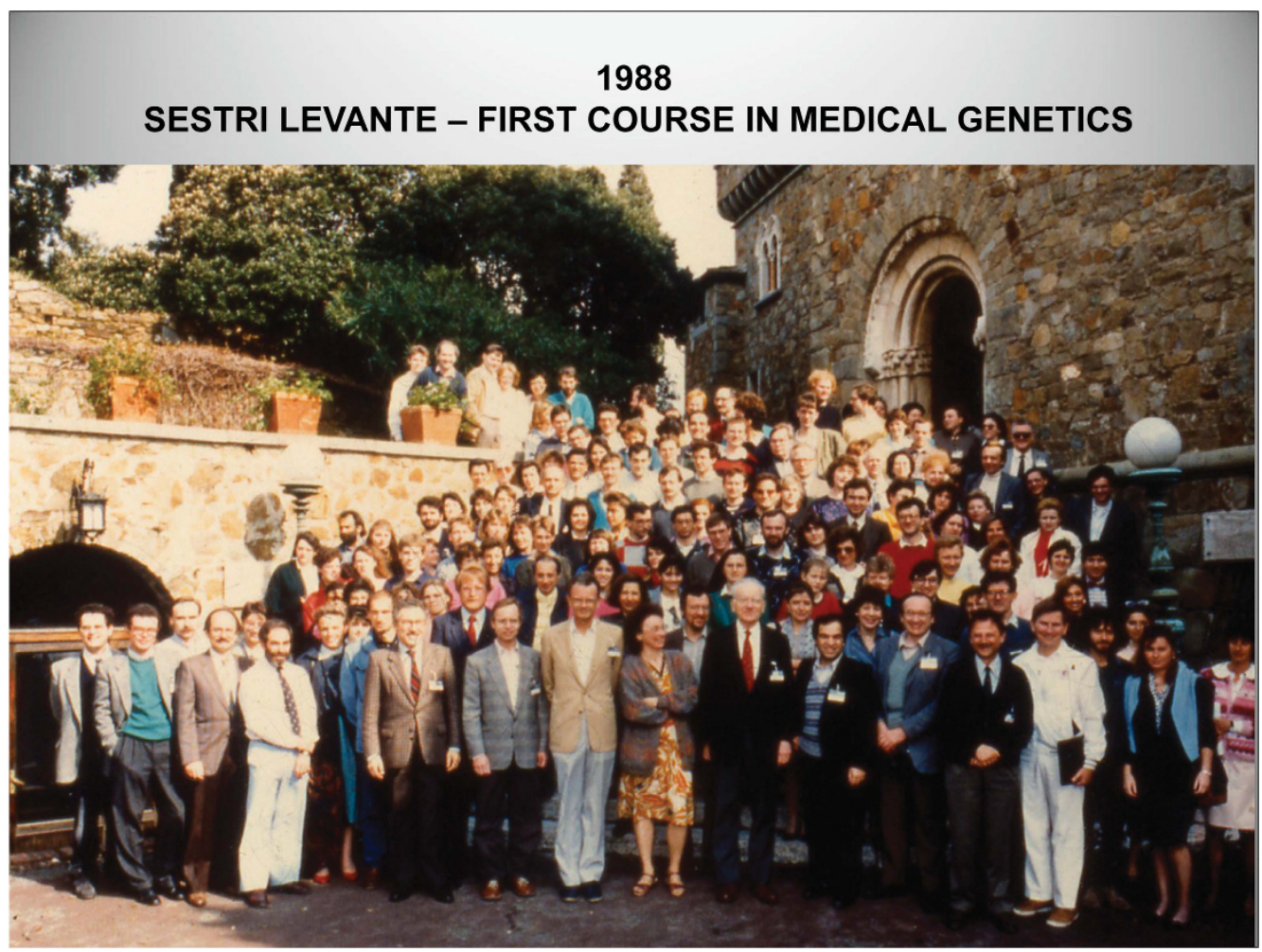

Figure 2

proposed by a committee consisting of Christos Bartsocas, Charles Buys, Marco Fraccaro, Peter Harper, Jan Mohr, Anne de Paepe and Eberhard Passarge) were approved and implemented in 1991 at the Leuven meeting where one of us (GR) took office as the first democratically elected ESHG President and went on to found the EJHG the following year. We have placed so much emphasis on the ESGM courses because we believe that the reform and expansion of the Society became possible in part through these courses, which enabled so many people to become acquainted with each other, breaking down national, regional and linguistic barriers.

Initially Jan Mohr, the founding secretary-general, contacted one of us (EP) in 1987 and suggested that he should take over as secretary-general in due time. Such a change appeared to be a good opportunity to make the ESHG more democratic and inclusive by electing a board (president, president-elect, secretary-general) and a programme committee. Supported by Peter Harper at the 1988 Cardiff meeting, the newly elected board took office in 1989 at the meeting in Groningen organised by Charles Buys (once again described by Peter Harper). All this happened at a time when Europe was going through great political changes-namely the fall of the Berlin Wall in November 1989, which led to the unification of East and West Germany in 1990, and the signing of major European treaties, such as Maastricht in 1993. It was a time of great enthusiasm and popular approval for the idea of building the European Union (EU) and implementing reforms, which for the first time in our history were being accomplished through peace and diplomacy.

In this climate of changes our small community of scientists was transformed into a democratic society of medical and clinical geneticists. We sometimes ask ourselves: was this achievement worth the time and effort invested in it? Among other indicators which can be used to answer this question, there is a simple observation based on the breakdown of students attending the main ESGM course in 1988 versus 2017 (Figures 1 and 4 respectively). This comparison documents the success of ESHG in supporting programmes of advanced training in medical and clinical genetics that today are no longer limited to Europe but attract young geneticists from all over the world. This is a tangible result which shows that the reformed ESHG is having a tremendous impact on the practice and research in medical genetics far beyond Europe. The spirit that animated the European School of Genetic Medicine since its early days in Sestri Levante probably imprinted many young geneticists like Brunhilde Wirth (a student in the course of 1988; Figure 2) and Han Brunner (a young faculty member since the early '90s) who later became the driving force of the main ESGM course.

In conclusion, the reform of ESHG was useful, as evidenced by the universal acceptance and recognition of the Society's role in medicine and genetics. The success of the ESHG today is also shown by its excellent annual meetings under the guidance of its programme committee, and by its Journal that serves to unite geneticists from all over Europe and to let the rest of the world know what is happening in Europe. The three authors of this review were actively involved in the transformation of the ESHG from a somewhat loosely organized association to a well-organised scientific society in the late 1980s and early 1990s. AdlC and GR served as presidents during that period, EP as secretary-general, all elected by the membership assembly at annual meetings. During his Presidency GR founded the Journal, which he directed until 1995. 


$$
\text { Numbering hand-outs }
$$

Istituto Scientifico G. Gaslini
International School of

International School of
Pediatric Sciences - Genoa

FEBS (Federation of European
Biochemical Societies)

EUROPEAN SCHOOL OF MEDICAL GENETICS
SESTRI LEVANTE (GenOa), APri1 $6-121988$
PROGRAM
$\frac{\text { WEDNESDAY }}{8.30-12.30} \div$
$1 \frac{\text { V.A.Mckusick }}{\text { introduction to }}$ (Baltimore): History of Medical Genetics: an 2 A.M. Frischauf (London): Introduction to molecular genetics $3 \frac{\text { G.Romeo (Genoa): DNA polymorphisms and disease }}{4 \text { A.Cao -(Cagliari): Beta-thalassemias: molecular basis, }}$
5 s.ottolenghi (Milano): Molecular mechanisms of defects in $\frac{\text { S.ottolenghi (Milano): Molecular mechanisms of defects in }}{\text { beta-thalassemias and inherited abnormalities of gamma-globin }}$

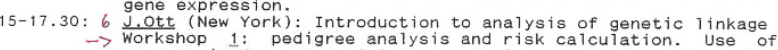 $\rightarrow$ workshop 1: pedigree analysis and risk calculation. Use of in Man, Possum, London Dysmorphology Database): demonstration of these programs will continue throughout the course. 18-18.30: Questions from students
$18.30-20:$ T.Caskey (Houston): Lesch-Nyhan disease: molecular basis,
neuropathology and mouse mode 1

$\frac{\text { THURSDAY }}{8.30-12.30}$

:8 B.Dallapiccola (Rome): Methods of cytogenetic analysis g. Ferguson-Smith (Cambridge): From chromosomal to molecular 10 C. Junien (Paris): Molecular characterization of constitutional 11M. Rocchi (Genoa): Cytogenetic methods for physical gene 15-17.30: $\rightarrow$ Workshop 2: Clinical cytogenetics

18-18.30: Questions from students
$18.30-20: 12$ A. de la Chapelle (He1sinki) and M.Ferguson-Smith (Cambridge): determination cytogenetic and molecular aspects of sex

$\frac{\text { FRIDAY }}{8.30-12.30} \stackrel{8}{*}$ Session on population gentics cordinated by R.cepelini

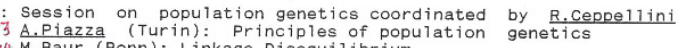

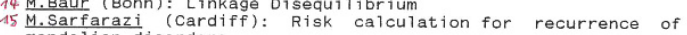
mendelian disorders

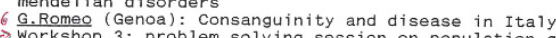

15-17.30: $\rightarrow$ Workshop 3 : problem solving session on population genetics 18.30-20: 17 R. Norio (He1sinki): The Finnish disease heritage

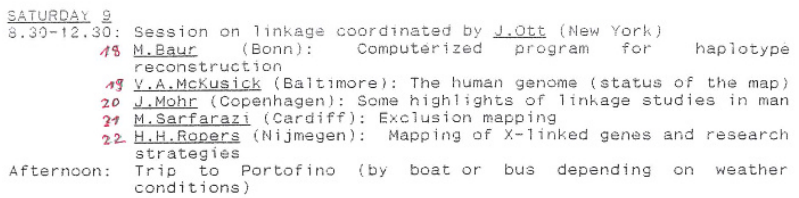

$\frac{\text { SUNDAY }}{8.30-12 \cdot 30} \frac{10}{23}$ A.M.Frischauf (London): The methods of reverse genetics

24 M. B. Bobrow (London): Duchenne muscular dystrophy

25 H. H.Ropers (Nijmegen): Myotonic dystrophy

$26 \frac{\text { G.Romeo (Genoa), J.Mohr (Copenhagen) and X.Estivill }}{\text { S. }}$ 15-17.30: $\rightarrow$ workshop 4: Molecular genetics (I) 27. A. Andria (Catanzaro), A.Ballabio (Naples), and M. Ferquson-
$28 \frac{\text { Smith (Cambridge): Molecular and clinical aspects of steroid }}{\text { sulphatase deficiency in man }}$ $\frac{\text { MONDAY }}{8.30-12} \frac{11}{30} \cdot \frac{29}{r}$

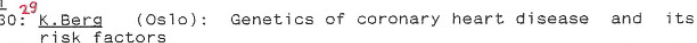
$30 \frac{\text { G. Utermann }}{\text { population variance of quantitative contributing to the }}$ population variance of quantitative lipoprotein traits and 31 G.Bianchi (Milan): Essential hypertension in man and in animal models 32 R.B.Barber (Milan): Selection and breeding of hypertensive
rats 33 A.Sidoli (Milan): Dislipoproteinemias, atherosclerosis and 15-17.30: $\rightarrow$ Workshop 5: Molecular genetics (II)

$18-18.30:$ Questions from students
$18.30-20: 34$ I.Caskey (Houston): Gene Therapy

$\frac{\text { TUESDAY }}{8,30-12}, \frac{12}{30}$

0: Session on prenatal diagnosis coordinated by J.C.Kaplan

35 M.Cordone (Genoa): ob-Gyn techniques

36 B. Dallapiccola (Rome): Cytogenetics

38 J.C.Kaplan (Paris): Strategies of prenatal diagnosis by DNA

39 M. DNA analysis and the associated counselling
Panel discussion on genetic counselling and prenatal diagnosis

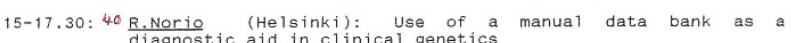
diagnostic aid in clinical genetics

18-18.30: Questions from students

18-18.30:
18.30-20: 41 G.Bernardi (Paris): The organization of the human genome

WEDNESDAY $\frac{13}{13}$

Figure 3 


\begin{tabular}{|l|c|}
\hline \multicolumn{1}{|c|}{ nationality } & pax \\
\hline ARGENTINA & 1 \\
\hline BELGIUM & 2 \\
\hline BOSNIA AND HERZI & 1 \\
\hline BULGARIA & 3 \\
\hline COLOMBIA & 1 \\
\hline CROATIA & 2 \\
\hline CUBA & 1 \\
\hline CZECK REP. & 3 \\
\hline DENMARK & 2 \\
\hline EGYPT & 3 \\
\hline FINLAND & 1 \\
\hline GEORGIA & 1 \\
\hline GERMANY & 4 \\
\hline GREECE & 3 \\
\hline HUNGARY & 2 \\
\hline IRAN & 7 \\
\hline ISRAEL & 5 \\
\hline ITALY & 5 \\
\hline LATVIA & 1 \\
\hline MOROCCO & 3 \\
\hline THE NETHERLANDS & 8 \\
\hline NORWAY & 2 \\
\hline OMAN & 2 \\
\hline POLAND & 2 \\
\hline PORTUGAL & 2 \\
\hline ROMANIA & 2 \\
\hline SAUDI ARABIA & 1 \\
\hline SERBIA & 1 \\
\hline SOUTH AFRICA & 1 \\
\hline SPAIN & 3 \\
\hline SUDAN & 1 \\
\hline SWEDEN & 3 \\
\hline SWITZERLAND & 2 \\
\hline TUNISIA & 1 \\
\hline TURKEY & 3 \\
\hline UK & 3 \\
\hline UNITED ARAB EMII & 1 \\
\hline & \\
\hline TOT. & \\
\hline
\end{tabular}

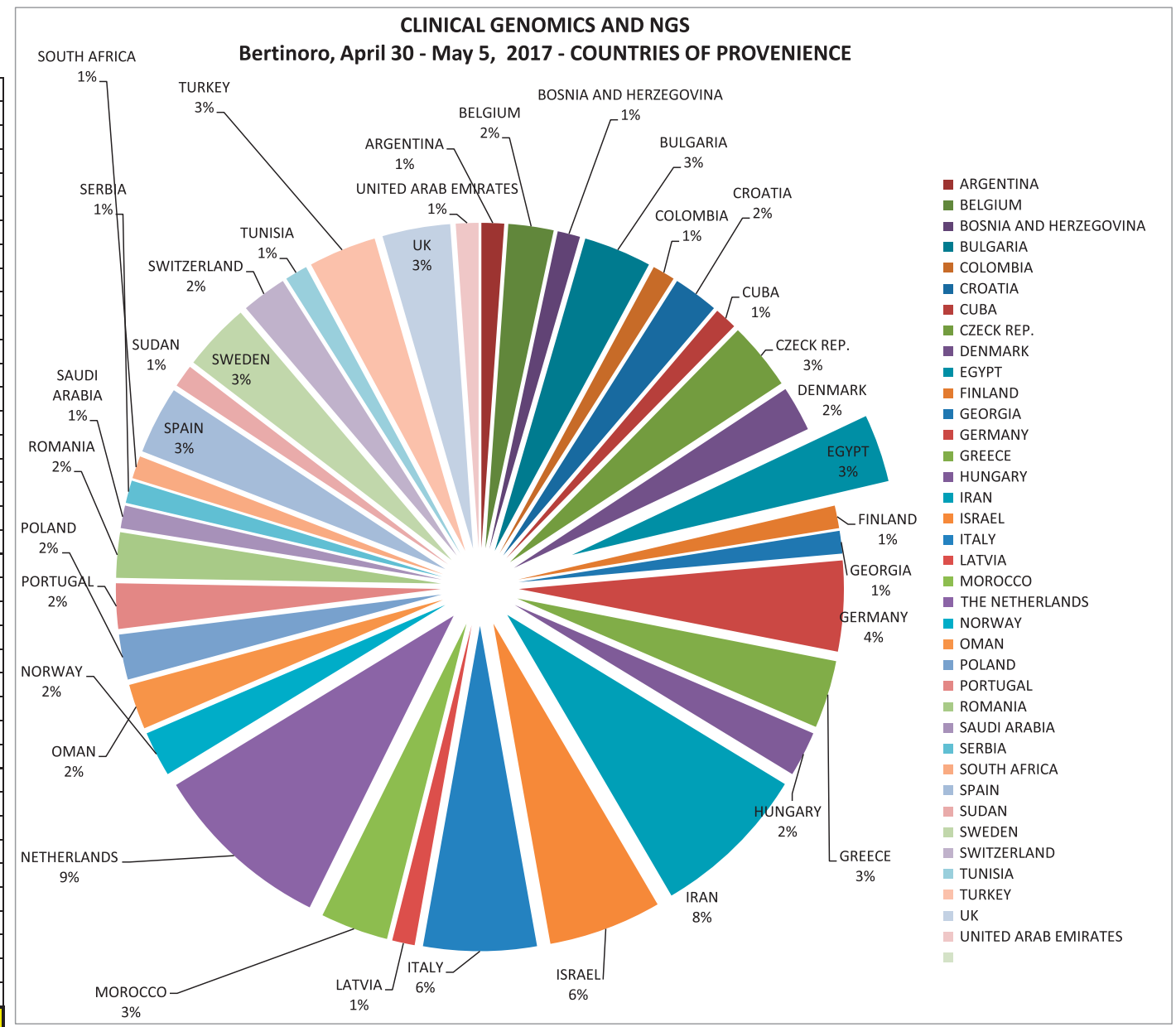

Figure 4 


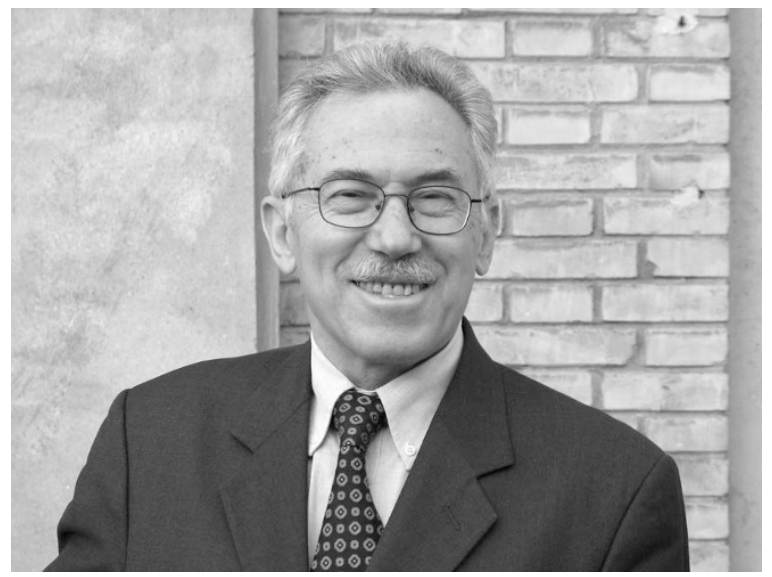

Giovanni Romeo

Professor of Medical Genetics at University of Bologna Medical School (2001-2012). Degree in Medicine (1965); Internship \& Residency in Paediatrics, University of Bologna Medical School (1965-1967); Research Fellow, Genetics Division, Department. of Pediatrics, Johns Hopkins Medical School, Baltimore, Md. (1968-1971).

Medical geneticist with a wide international research experience documented by his leadership role during the past 30 years in different Institutions: Genova (Istituto G Gaslini), Lyon (International agency for Research on Cancer) and Bologna Medical School. Major research interests: Hirschsprung disease, RET protooncogene, consanguinity studies and genetic epidemiology, mtDNA mutations in cancer. He has published more than 380 papers in peer-reviewed international journals.

In collaboration with the late Prof. Victor McKusick in 1988 he founded the European School of Genetic Medicine, now located in Bertinoro, Italy, attended so far by more than 7000 students and devoted to the advanced training in genetics and genomics of young geneticists and health professionals from Europe and elsewhere in the world.

In 1992 he became the first democratically elected President of the European Society of Human Genetics (ESHG) and founded the European Journal of Human Genetics which he directed up to 1995.

Among other prizes, he was awarded the ESHG Educational Award in 2005 and the Arno Motulsky-Barton Child Award for Excellence in Human Genetics Education in 2011 by the American Society of Human Genetics. During the past 15 years he developed several research and educational projects in Oman. 


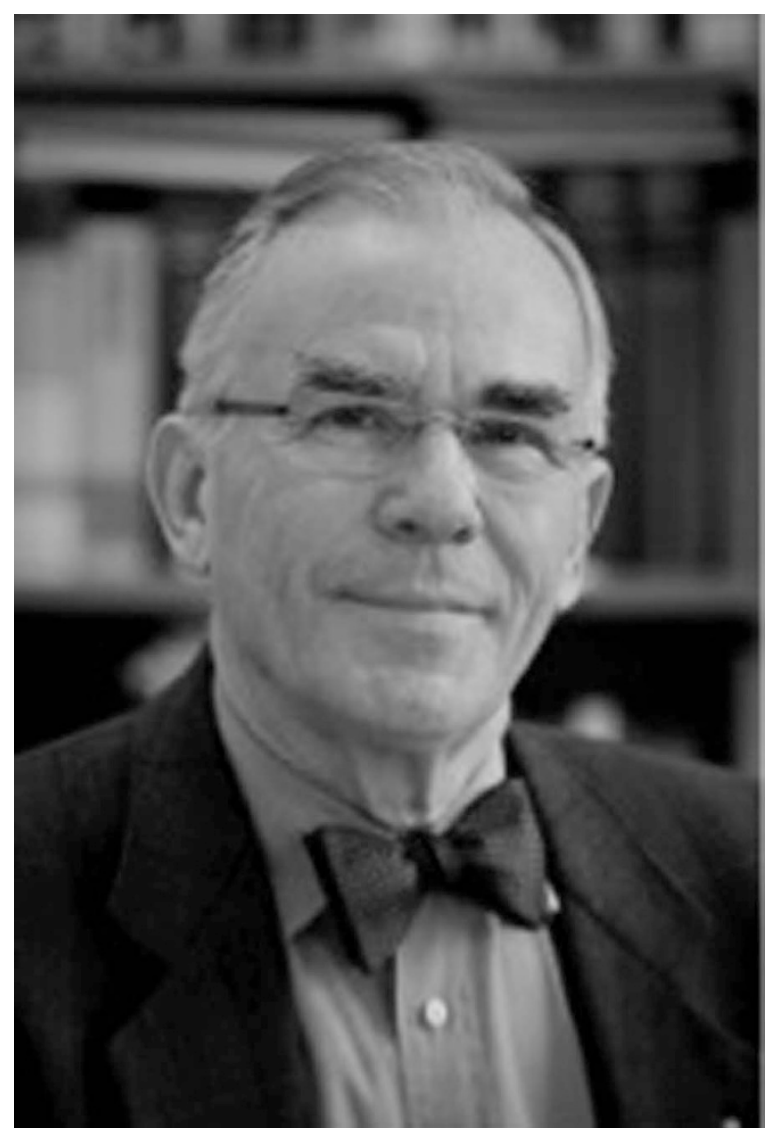

Eberhard Passarge, MD (1935), is a US-trained German human geneticist at the Medical Faculty Essen of the University of Duisburg-Essen, Germany. He became a founding member of the ESHG after attending the discussion of forming a European Society of Human Genetics at the Third International Congress of Human Genetics 1966 in Chicago. He served as secretary-general of the ESHG 1989-1991. He was host of the annual meeting of the ESHG in Essen in 1984 on 'Cancer and Genetics'.

He graduated as MD at the University of Freiburg (1960), had postgraduate training in Hamburg and Worchester (MA), specialized in Paediatrics and Genetics in Children's Hospital Cincinnati, Ohio and Cornell Medical Center New York. He was Head of the Division of Cytogenetics and Clinical Genetics at the Department of Human Genetics, University of Hamburg, Germany, 1968-1976, and moved to Essen in 1976. From 2010-2014 he was Intermediary Chairman, Department of Human Genetics, University of Leipzig, Germany.

His main interests are the scientific investigation of hereditary and congenital diseases and the application of this knowledge in genetic diagnosis and counseling. He is author or co-author of about 250 articles in international, peer-reviewed journals. His experience in academic teaching is reflected in his single author book Color Atlas of Genetics, its 5th edition in press, to be published by Thieme Medical Publishers Stuttgart-New York, in 2018.

EP was President of the German Society of Human Genetics 1990-1996, of which he became an honorary member in 2011. He is music coordinator at the University of Duisburg-Essen where he organizes the annual festive university concert. He was elected to be an honorary member of the university senate in 2016. He was awarded prizes from scientific institutions in Germany, Romania, Czech Republic, and India.

(Institute of Human Genetics, Emeritus Director, University Hospital Essen, Hufelandstr. 52, 45122 Essen, Germany) 


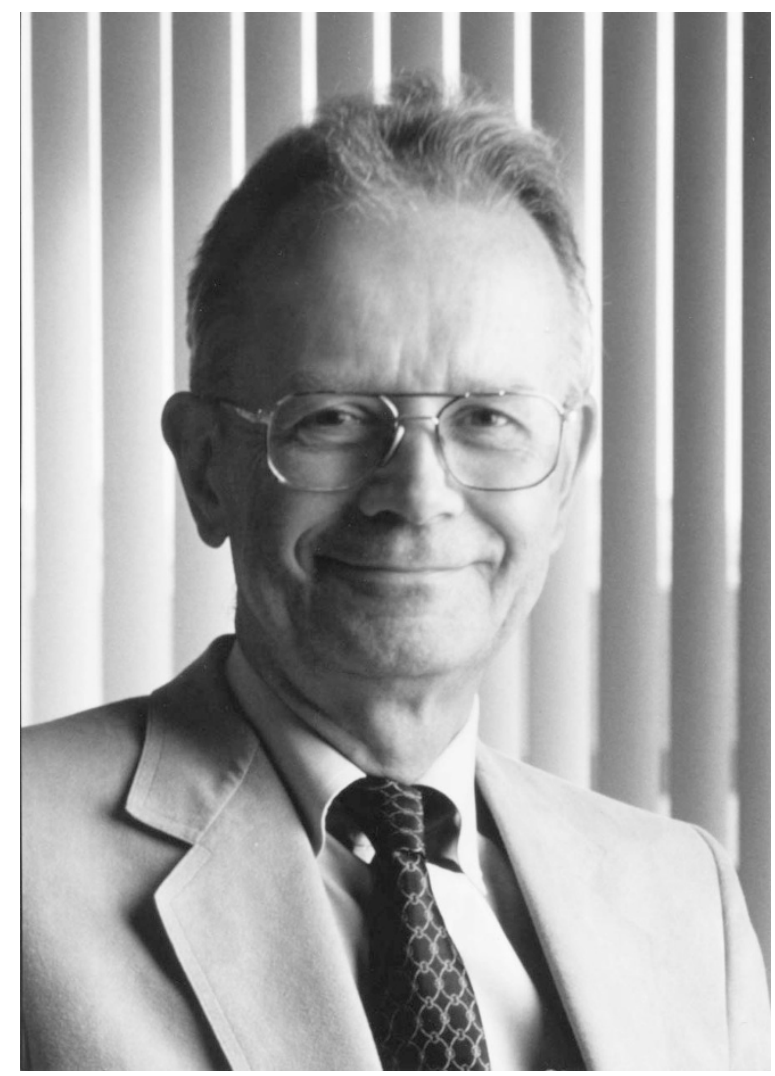

Albert de la Chapelle is a Distinguished University Professor and Cancer Scholar at The Ohio State University. He received his MD in 1957 and $\mathrm{PhD}$ in Human Genetics in 1962 at the University of Helsinki. He received board certification in Internal Medicine but soon left clinical medicine for genetics. He became Finland's first Professor of Medical Genetics in 1974 and remained at that position until 1997 when he moved to The Ohio State University to start a program in Human Cancer Genetics. In the European Society of Human Genetics he served as a Board member 1966-1995, Chairman of the Aims and Statutes Committee 1990-1991, and President 1993-1994. His major honors include: Memberships in the Academy of Finland, the Royal Swedish Academy of Sciences and the US National Academy of Sciences. Dr de la Chapelle started as a cytogeneticist specializing in mechanisms of sex determination. He then turned to molecular genetics, pioneering the mapping and cloning of those Mendelian disorders that are enriched in the Finnish founder population, clarifying the molecular basis of over a dozen of these disorders. He is best known for his role in determining the molecular basis of hereditary cancer, notably the role of the mismatch repair genes in Lynch syndrome. He detected the phenomenon of microsatellite instability in hereditary cancer. He has pioneered the translation of these molecular events into clinical work and cancer prevention. Presently his laboratory is heavily committed to the study of the genetics of thyroid cancer. 